\title{
GWO Based Optimal Reactive Power Coordination of DFIG, ULTC and Capacitors
}

\author{
Mogaligunta Sankaraiah ${ }^{1}$, S. Suresh Reddy ${ }^{2}$, M. Vijaya Kumar ${ }^{3}$ \\ ${ }^{1,3}$ Electrical \& Electronics Engineering, JNTUA, Ananthapuramu, 515002, India \\ ${ }^{2}$ Electrical \& Electronics Engineering, N.B.K.R.I.S.T, Vidy anagar, SPSR Nellore district, 524413, India
}

\begin{abstract}
Article Info
\section{Article history:}

Received Mar 6, 2018

Revised Apr 28, 2018

Accepted Jun 10, 2018

\section{Keywords:}

Doubly Fed Induction Generator (DFIG)

Grey Wolf Optimization

Algorithm (GWO)

On Load Tap Changer (ULTC)

ABSTRACT

Wind is available with free of cost anywhere in the world, this wind can be used for power generation due to many advantages. This attracts the researchers to work on wind power plants. The presence of wind power plants on distribution system causes major influence on voltage controlled devices (VCDs) in terms of life of the devices. Therefore, this paper proposes grey wolf optimization method (GWO) together with forecasted load one day in advance. VCDs are on load tap changer (ULTC) and capacitors (CS), there are two main objectives first one is curtail of distribution network (DN) loss and second one is curtailing of ULTC and CS switching's. Objectives are achieved by controlling the reactive power of DFIG in coordination with VCDs. The proposed method is planned and applied in Matlab/Simulink on $10 \mathrm{KV}$ practical system with DFIG located at different locations. To validate the efficacy of GWO, results are compared with conventional and dynamic programming methods without profane grid circumstances.
\end{abstract}

Copyright (C) 2018 Institute of Advanced Engineering and Science. All rights reserved.

\section{Corresponding Author:}

Mogaligunta Sankaraiah,

Electrical \& Electronics Engineering, JNTUA,

Ananthapuramu, 515002, India.

Email: sankar.neeru@gmail.com

\section{INTRODUCTION}

Today the entire world focusing on Distributed generation because of non availability of input sources for conventional power generating stations and too many advantages of distributed generation (DG). Wind power is one of the best sources in DG, this attracts the research people to work on this [1]. In [2-3], Co-Evolutionary particle swarm algorithm and Artificial immune system are proposed for optimal placement and sizing of DGs. DGs are affecting the voltage stability of distribution [4-5]. These papers focused only on optimal placement and impact on voltage stability in the presence of DGs. Generally these DGs are directly connected to distribution system, which influences the power loss and switching operations of ULTC and capacitors, therefore the useful life of these devices are decreasing [6]. In [7] VCDs (ULTC \& CS), DG and automatic voltage regulator (AVR) are coordinated, which reported that because of DG the switching operations of devices (SODs) are greatly increased almost more than three times as compared with without DG. SODs are increased more than two times, when VCDs and DG coordinated by SCADA system [8]. In [9-10] VCDs are coordinated using two different approaches, first one is dynamic programming and second one is combined voltage control. In all these methods DGs are not included while dis patching the reactive power.

In [11], synchronous machine as a DG and this reactive power is coordinated in the presence of VCDs. In [12], an autonomous system is taken including DG and real power of DG is coordinated together with power loss by optimal power flow approach. In [13-17], coordination done by TRSQP method, asynchronous and synchronous generators coordinated together with VCDs by voltage control, adaptive and 
dynamic programming approaches are used for coordination respectively. All these methods are giving more importance for dispatchable DGs and the importance given for non dispatchable DGs are very small.

The objectives of this paper are reduction of power loss and switching operations of VCDs in the presence of DFIG. This can achieve by coordinating the reactive power DFIG and VCDs. This paper proposes grey wolf optimizer algorithm for reactive power coordination of DFIG, ULTC and Shunt capacitors in order to reduce power loss and switching operations of ULTC and Shunt capacitors.

\section{MATHEMATICAL MODELLING OF DFIG}

Mathematical modelling of DFIG is very important, which affects the output of DFIG and therefore losses and SODs. Input to DFIG is wind, which is not constant throughout a day or hour, so, the output of DFIG also changes. In mathematical modelling a relation is developed between input and output in terms of probability density function (PDF). This PDF describes the availability of wind based on that we can est imate the output of DFIG [18]. In generally wind speed of wind farm nearly similar to weibull distribution for particular time at a particular location [19]. Now the PDF can be written as:

$$
\begin{aligned}
& P D F(\text { vel })=\frac{S F}{S C F} \times\left(\frac{v e l}{S C F}\right)^{S F-1} \times \exp ^{-(v e l \times S C F)^{S F}} \\
& W P D F(\text { vel })=1-\exp ^{-\left(\frac{v e l}{S C F}\right)^{S F}}
\end{aligned}
$$

In Equations $1 \& 2, P D F(v e l), W P D F(v e l), S F, S C F$, vel, exp,denotes probability density function, weibull PDF, shape factor, scale factor, wind velocity and exponential respectively.

Based on Equations $1 \& 2$ the output of DFIG is characterised into three parts based on wind velocity. If wind speed is below cut in speed and above cut off speed the output of DFIG is taken as ' 0 '. If wind speed is above cut in and below rated the output of DFIG is written as $0.5 \times A D \times(R R B)^{2} \times M P C \times(v e l)^{3}$. In remaining cases output is written as $R P$. Where $A D, R R B$ $M P C$ and $R P$ represents air density, rotor blade radius, maximum coefficient related to performance and rated power respectively. Figure 1 shows the power availability of DFIG with respect to speed [20-21]. Figure 2 shows single line diagram of system with distributed generation.

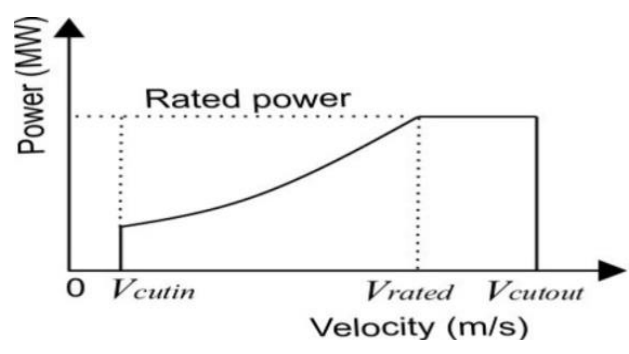

Figure 1. DFIG output characteristic

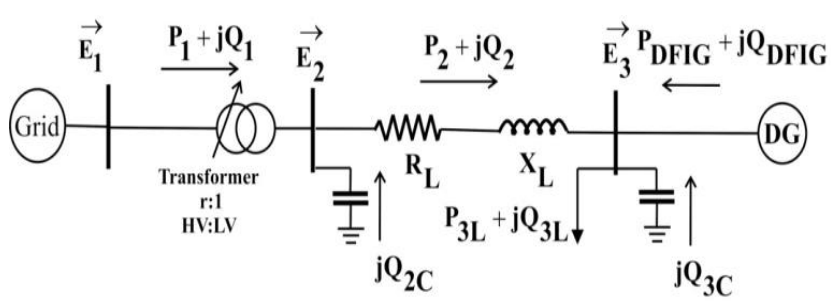

Figure 2. Single line diagram of system with distributed generation

\section{PROBLEM FORMULATION}

There are two main objectives of this paper; first one is reduction of SODs and second one is system power loss reduction. The objective function is modelled as a multi objective function; Figure 2 is used for this purpose.

Where $E$ represents voltage, suffix 1 represents grid, suffix 2 and 3 indicates sending and receiving ends respectively, suffix DFIG indicates DG as a DFIG, P \& Q indicates real power and reactive power respectively. $R_{L}$ And $X_{L}$ indicates line resistance and reactance, suffix $2 \mathrm{C}$ and $3 \mathrm{C}$ indicates capacitor at sending end and receiving end respectively. 
The first objective, power loss is shown in Equation 3 is written by taking receiving end voltage as a reference. Power loss of the line is proportional to current and line resistance, therefore power loss can be written as:

$$
P_{L L}^{h}=I_{L}^{2} \times R_{L}
$$

After substituting the value of current in terms of sending end voltage and receiving end voltage, the power loss equation is writer as:

$$
P_{L L}^{h}=\left|\frac{E_{2} \times \cos (\delta)+j E_{2} \times \sin (\delta)-E_{3}}{R_{L}+j X_{L}}\right|^{2} \times R_{L}
$$

The second objective is written by considering one ULTC with a tap of ' $r$ ' and two capacitors one is at sending end and another is at receiving end:

$$
\operatorname{SODS}^{h}=f(\text { tap,capacitor })
$$

Generally capacitors at sending end and receiving end are more than one in number. Objective function is expressed as:

$$
O B F=P_{L L}^{h}+S O D s^{h}
$$

Where ' $h$ ' stands for hour, power loss and SODs are multiplied with cost weighting factors to get general multi objective function. The multi objective function is written as;

$$
O B E=\min \sum_{h=1}^{24}\left(C P \times P_{L L}^{h}+C_{1} \times\left|r^{h}-r^{h-1}\right|+C_{2} \times\left|K_{S b}^{h}-K_{S b}^{h-1}\right|+C_{3} \times\left|K_{F c}^{h}-K_{F c}^{h-1}\right|\right)
$$

Constraints are listed in the following way:

Equality constraints

$$
\begin{aligned}
& P_{D G}-P_{L}=P_{\text {Loss }} \\
& Q_{D G}-Q_{L}=Q_{\text {Loss }}
\end{aligned}
$$

Inequality constraints

$$
\begin{aligned}
& Q_{D G}^{\min } \leq Q_{D G} \leq Q_{D G}^{\max } \\
& E^{\min } \leq E \leq E^{\max } \\
& r^{\min } \leq r \leq r^{\max } \\
& K_{S c}^{\min } \leq K_{S c} \leq K_{S c}^{\max } \\
& K_{F c}^{\min } \leq K_{F c} \leq K_{F c}^{\max }
\end{aligned}
$$

Here $C P, C_{1}, C_{2}$, and $C_{3}$ are the cost weighting factor for power loss, ULTC, substation capacitors and feeder capacitors respectively. $K_{S c}$ and $K_{F c}$ are indicating number of capacitors at substation and feeders respectively. 


\section{GREY WOLF OPTIMIZER ALGORITHM (GWO)}

The multi objective function formulated and indicated in equation 3 requires qualitative algorithm for generating the best result among different combinations. Too many algorithms are available like evolutionary based, SI based and physics based. Among evolutionary Genetic algorithm is most powerful and best algorithm proposed in 1992 [22-23]. The remaining some of the important algorithms under this group are differential evolution, evolutionary programming and strategy [24-25]. Some of the important physics based algorithms are GLSA [26], BBBC [27], GSA [28], and ACROA [29], in the SI group the important algorithms are terminate algorithm (TA) [30], Bee collecting pollen algorithm (BCPA) [31], Monkey search algorithm (MS) [32] and Wasp swarm algorithm (WSA) [33].

The algorithms listed above inspired by exploration and hunting behaviours, there is no algorithm which apes both the behaviours in leadership hierarchy, therefore this paper proposes GWO algorithm [34] for solving multi objective function, which ape hunting, exploration in a leadership hierarchical. This algorithm follows three major steps, first step involves look, pursue and move towards the quarry. Second step involves chase, surround and has sle the quarry. Third step involves hitting the quarry.

\subsection{GWO Implementation to Objective Function}

Implementation of GWO algorithm is as follows:

Step 1: Set all initial conditions.

The values of cost weighting factors $C P, C_{1}, C_{2}$ and $C_{3}$, number of searching agents, maximum iterations, number of parameters to be tuned and their minimum and maximum limits, initial values for alpha, beta and delta, forecasted load.

Step 2: Calculate power loss in the system for first hour

Run Backward/Forward algorithm with initial values and calculate power loss and voltages at all the buses in the system.

Step 3: Calculate Objective function value of each search agent

With obtained power loss in step 2, with initial values of parameters and their cost weighting factors calculate objective function value of each search agent.

Step 4: Update voltages

Run Backward/Forward algorithm with updated search agents and update all buses voltages.

Step 5: Fitness function calculation

Calculate the fitness function value using equation 2 .

Step 6: Update alpha, beta and delta

If fitness value is less than alpha score then update alpha with alpha score is equal to fitness, if fitness is greater than alpha score but less than beta score update beta with beta score is equal to fitness, if fitness is greater than alpha score and beta score but less than delta score then update delta with delta score is equal to fitness value.

Step 7: Update positions of search agents including omega

Generate two random numbers $\mathrm{Rn} 1, \mathrm{Rn} 2$ and then evaluate matrix B \& $\mathrm{C}$ using the following equations 15-16, update the distance of each search agent with the help of equations 17-20.

$$
\begin{aligned}
& B=2 \times a \times R n 1-a \\
& F=2 \times R n 2 \\
& D_{\text {alpha }}=F \times P_{\text {alpha }}-\text { Best }_{\text {alpha }} \\
& D_{\text {beta }}=F \times P_{\text {beta }}-\text { Best }_{\text {alpha }} \\
& D_{\text {delta }}=F \times P_{\text {delta }}-\text { Best }_{\text {alpha }} \\
& D_{\text {omega }}=F \times P_{\text {omega }}-\text { Best }_{\text {alpha }}
\end{aligned}
$$

Where $\mathrm{P}$ indicates present position, $\mathrm{D}$ indicates distance and Best indicates present best position. Step 8: Update parameters to be tuned

Based on the positions of search agents update the parameters which are to be determined. 
Step 9: Update voltages

Run Backward/Forward algorithm with updated search agents and update all buses voltages.

Step10: Repeat steps 2 to 9 for remaining hours

In this paper the total time is spatter into 24 hours, therefore, repeat the same procedure using steps 2 to 9 .

Step11: Stopping criteria

If iterations are completed then stop and display best results in every hour.

\section{TEST SYSTEM}

$10 \mathrm{KV}$ practical system which is used for testing purpose is shown in Figure 3. This system consists of 16 buses or nodes, one transformer with 32 steps ULTC, four groups of capacitor banks, three feeders and loads at all buses other than bus $16 \& 1$. Transformer is 40MVA, 70/10KV rating, one capacitor bank with three capacitors each 2.5MVAR rated is connected at bus 1, second capacitor bank with five capacitors each with a rating of 1.5MVAR connected at bus 4, third capacitor bank with five 1.5MVAR capacitors connected at bus 9 and fourth capacitor bank with four 1.5MVAR capacitors are connected at bus 13 .

In order to reduce the power loss and SODs, the load is forecasted one day in advance and is shown in Table 1. In this table only real power for 24 hours at all the buses are indicated, from the real power we can find the reactive power at each bus by taking its power factor. The power factor of all loads is taken as 0.8 lagging. Figure 4 shows the expected real power of DFIG over 24 hours time from this reactive power is estimated by taking power factor of 0.9 lag/lead.

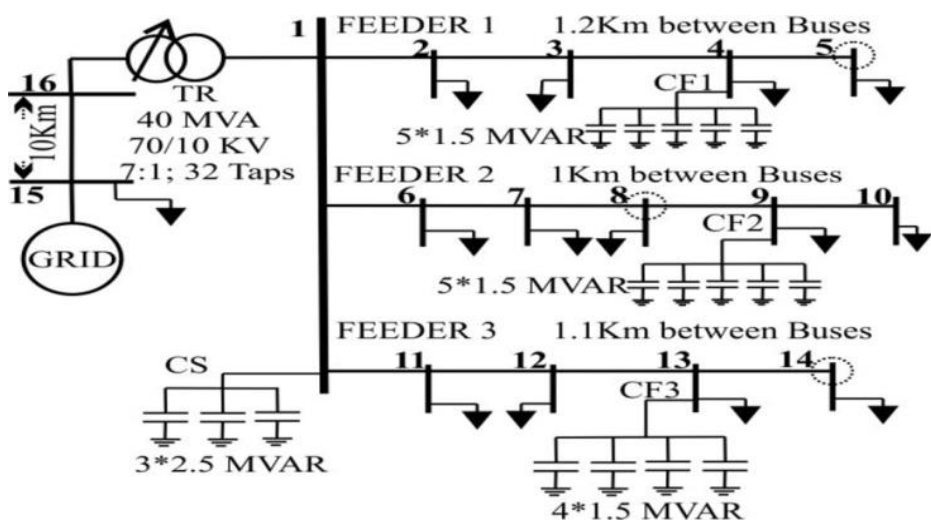

Figure 3. $10 \mathrm{KV}$ test system

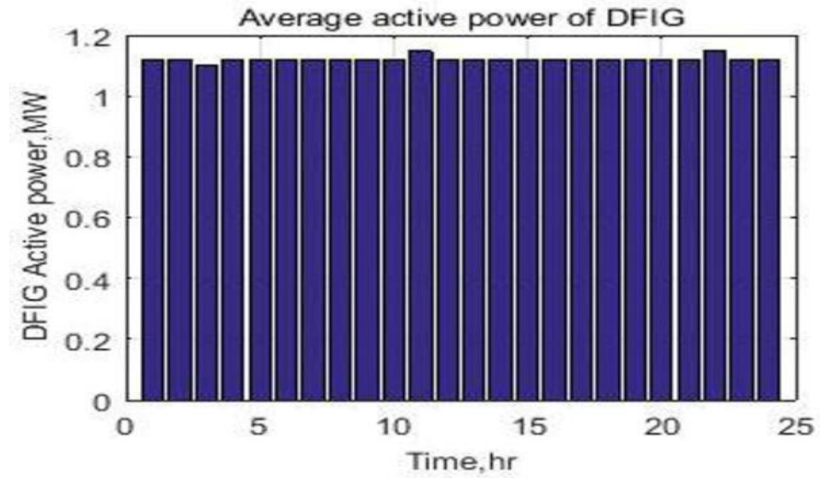

Figure 4. DFIG expected real power over 24 hours 
Table 1. Forecasted Load Over 24 Hours

\begin{tabular}{|c|c|c|c|c|c|c|c|c|c|c|c|c|c|c|c|c|}
\hline & \multicolumn{16}{|c|}{ Feeder Bus numbers } \\
\hline 2 & 0.0 & 1.0 & 0.7 & 0.4 & 0.8 & 0.2 & 0.1 & 0.4 & 0.2 & 0.4 & 1.3 & 1.5 & 1.4 & 1.6 & 5.0 & 0.0 \\
\hline 4 & 0.0 & 0.3 & 0.7 & 0.2 & 0.3 & 0.5 & 0.5 & 0.6 & 0.7 & 0.8 & 1.4 & 1.2 & 1.7 & 1.7 & 5.0 & 0.0 \\
\hline 5 & 0.0 & 0.6 & 0.6 & 0.7 & 0.9 & 1.1 & 0.7 & 0.8 & 0.9 & 0.8 & 1.3 & 1.3 & 1.6 & 1.8 & 5.0 & 0.0 \\
\hline 6 & 0.0 & 1.7 & 1.7 & 1.3 & 1.2 & 1.2 & 0.9 & 0.7 & 1.1 & 1.0 & 1.2 & 1.1 & 1.5 & 1.4 & 5.0 & 0.0 \\
\hline 9 & 0.0 & 2.1 & 2.3 & 2.1 & 2.4 & 1.6 & 1.6 & 1.5 & 1.9 & 1.8 & 0.7 & 0.8 & 1.0 & 0.9 & 5.0 & 0.0 \\
\hline 10 & 0.0 & 2.6 & 2.2 & 2.3 & 2.9 & 2.1 & 2.0 & 2.1 & 1.8 & 1.9 & 1.5 & 1.1 & 1.2 & 1.3 & 5.0 & 0.0 \\
\hline 11 & 0.0 & 2.9 & 2.7 & 2.8 & 3.2 & 2.0 & 2.3 & 2.5 & 2.0 & 2.1 & 1.8 & 1.7 & 1.4 & 1.6 & 5.0 & 0.0 \\
\hline 12 & 0.0 & 2.2 & 2.1 & 2.7 & 1.9 & 1.4 & 1.9 & 2.2 & 1.6 & 1.9 & 1.2 & 1.4 & 1.3 & 1.4 & 5.0 & 0.0 \\
\hline 13 & 0.0 & 2.9 & 2.9 & 3.0 & 3.2 & 2.3 & 2.9 & 3.0 & 2.4 & 2.1 & 1.5 & 1.6 & 1.8 & 1.4 & 5.0 & 0.0 \\
\hline 14 & 0.0 & 3.1 & 3.2 & 3.5 & 3.3 & 2.7 & 3.1 & 3.0 & 2.7 & 1.2 & 1.7 & 1.8 & 1.8 & 1.4 & 5.0 & 0.0 \\
\hline 18 & 0.0 & 2.5 & 2.7 & 2.9 & 2.4 & 2.4 & 2.1 & 1.8 & 1.8 & 1.2 & 1.9 & 2.1 & 2.0 & 2.2 & 5.0 & 0.0 \\
\hline 19 & 0.0 & 2.0 & 2.0 & 2.0 & 1.8 & 1.8 & 1.4 & 1.3 & 1.2 & 1.3 & 1.9 & 2.1 & 2.0 & 2.2 & 5.0 & 0.0 \\
\hline 20 & 0.0 & 1.6 & 1.6 & 1.8 & 1.7 & 1.4 & 1.3 & 1.3 & 1.1 & 1.3 & 1.9 & 2.0 & 1.5 & 1.5 & 5.0 & 0.0 \\
\hline 21 & 0.0 & 1.6 & 1.4 & 1.7 & 1.5 & 1.3 & 1.4 & 1.2 & 1.1 & 1.2 & 1.8 & 1.9 & 1.5 & 1.4 & 5.0 & 0.0 \\
\hline 22 & 0.0 & 1.2 & 1.3 & 1.4 & 1.2 & 0.6 & 0.9 & 1.1 & 1.2 & 1.1 & 1.8 & 1.7 & 1.8 & 1.3 & 5.0 & 0.0 \\
\hline 23 & 0.0 & 1.2 & 1.0 & 1.3 & 1.1 & 0.5 & 0.6 & 1.3 & 0.8 & 1.2 & 1.6 & 1.6 & 1.8 & 1.7 & 5.0 & 0.0 \\
\hline 24 & 0.0 & 1.0 & 0.9 & 0.6 & 0.9 & 0.5 & 0.2 & 0.8 & 0.6 & 1.2 & 1.7 & 1.7 & 1.6 & 1.1 & 5.0 & 0.0 \\
\hline
\end{tabular}

\section{RESULTS \& DISCUSSION}

Test system shown in Figure 4 is simulated with load shown in Table 1 and DG output shown in Figure 5. DG is placed at three different locations and in each location the simulation results are listed in Tables 2 to 4. Conventional method represents power loss of 13.69MWh, ULTC is changing 6 times, substation capacitors are changing 14 times, capacitors at feeder 1 changes 10 times and capacitors at feeder 2 and 3 changes 10 times and six times respectively with DG connected at bus 5 in feeder 1 . If DG is connected to feeder 2 at bus 8, conventional method reported that $13.9 \mathrm{MWh}$ power loss, 6 times ULTC variations, 14 times substation capacitors variations, 10 variations in feeder 1 capacitors, 10 variations in feeder 2 capacitors and 6 variations in feeder 3 capacitors. In similarly power loss, ULTC and Capacitor variations are shown in Table 4. In conventional method DG is operating at unity power factor, therefore, power loss and SODs are more.

Simulation results with dynamic programming (DP) are reported in Tables 2 to 4 . In Table 2, 13.67MWh is the power loss; there are 6 changes in ULTC, 12, 8, 6, 4 changes in substation capacitors, feeder 1 capacitors, feeder 2 capacitors and feeder 3 capacitors respectively. From Table 3, 13.83MWh power loss; 6, 12, 10, 8, 4 variations in ULTC, substation capacitors, feeder 1 capacitors, feeder 2 capacitors and feeder 3 capacitors are noted respectively. Similarly DG at 14 results is shown in Table 4 . In dynamic programming method reactive power of the DG is considered [16]. Results with grey wolf optimizer are reported in Tables 2 to 4 with DGs at 5, 8 and 14 respectively. From the results listed in Tables 2 to 4, reactive power of DG is properly utilized by GWO method as compared with Dynamic programming and conventional methods $(\mathrm{CO})$.

DG at 5 , GWO reduces power loss by $2.0606 \mathrm{MWh}$ as compared with conventional and $2.0406 \mathrm{MWh}$ as compared with DP, ULTC switching operations are also reduced by 4 times compared with CO and DP, substation capacitor switching operations reduced by 14 and 12 times compared with CO and DP respectively, feeder capacitors switching operations are reduced by 21 times and 13 times compared with $\mathrm{CO}$ and DP. DG at 8 , GWO reduces power loss by $3.5105 \mathrm{MWh}$ as compared with conventional and $3.4405 \mathrm{MWh}$ as compared with DP, ULTC switching operations are also reduced by 4 times compared with CO and DP, substation capacitor switching operations reduced by 12 and 10 times compared with CO and DP respectively, feeder capacitors switching operations are reduced by 19 times and 15 times compared with CO and DP. DG at 14, GWO reduces power loss by $3.1191 \mathrm{MWh}$ as compared with conventional and 3.0591MWh as compared with DP, ULTC switching operations are also reduced by 5 times compared with CO and DP, substation capacitor switching operations reduced by 14 and 12 times compared with CO and DP respectively, feeder capacitors switching operations are reduced by 25 times and 21 times compared with $\mathrm{CO}$ and DP.

Table 5 reports the cost comparison of three methods with DG at 5,8 and 14 locations. Cost of power loss, switching loss and total are calculated using the equations 21 to 23. From this table, DP method 
reduced power loss by $0.146 \%$ and GWO method reduced power loss by $15.05 \%$ as compared with CO method, switching operations of VCDs are reduced by $18.64 \%$ in DP and $84.745 \%$ in GWO compared with $\mathrm{CO}$ and also total cost reduced by DP is $12.78 \%$ and GWO by $62.65 \%$ in comparison with CO if DG is located at 5. If DG is located 8, DP reduces power loss, switching operations of VCDs and total power loss by $0.5035 \%, 11.864 \%$ and $8.225 \%$ respectively compared with $\mathrm{CO}$, GWO reduces power loss, switching operations of VCDs and total power loss by $25.2554 \%, 74.576 \%$ and $58.779 \%$ respectively compared with CO. If DG at 14, DP reduces power loss, switching operations of VCDs and total power loss by $0.4264 \%$, $11.475 \%$ and $7.987 \%$ respectively compared with $\mathrm{CO}$, GWO reduces power loss, switching operations of VCDs and total power loss by $22.168 \%, 91.80 \%$ and $69.82 \%$ respectively compared with CO.

$$
\text { Powerlos }(\$)=80 \times \text { powerlos }(\mathrm{MWh})
$$

Switchingdss $(\$)=80 * U L T C+60 * C S+40 *(C F 1+C F 2+C F 3)$

$$
\text { Totallos }(\$)=\text { Powerlos }(\$)+\text { Switchingdss }(\$)
$$

\begin{tabular}{|c|c|c|c|c|}
\hline \multicolumn{2}{|c|}{ DG Location } & \multicolumn{3}{|c|}{ At Bus 5} \\
\hline \multirow{2}{*}{\multicolumn{2}{|c|}{$\begin{array}{l}\text { Control Methods } \\
\text { Power loss (MWh) }\end{array}$}} & Conventional & Dynamic programming & Grey wolf optimizer \\
\hline & & 13.69 & 13.67 & 11.6294 \\
\hline & ULTC & 6 & 6 & 2 \\
\hline Switching & CS & 14 & 12 & 0 \\
\hline operations & $\mathrm{CF} 1$ & 10 & 8 & 2 \\
\hline \multirow[t]{2}{*}{ of VCDs } & $\mathrm{CF} 2$ & 10 & 6 & 2 \\
\hline & CF3 & 6 & 4 & 1 \\
\hline \multicolumn{2}{|c|}{ Power loss (\$) } & 1095.2 & 1093.6 & 930.352 \\
\hline \multicolumn{2}{|c|}{ Switching Loss(\$) } & 2360 & 1920 & 360 \\
\hline \multicolumn{2}{|c|}{ Total Loss $(\$)$} & 3455.2 & 3013.6 & 1290.352 \\
\hline
\end{tabular}

Table 2. DG Located at Bus 5

\begin{tabular}{|c|c|c|c|c|}
\hline \multicolumn{2}{|c|}{ DG Location } & \multicolumn{3}{|c|}{ At Bus 8} \\
\hline \multirow{2}{*}{\multicolumn{2}{|c|}{$\begin{array}{l}\text { Control Methods } \\
\text { Power loss (MWh) }\end{array}$}} & Conventional & Dynamic programming & Grey wolf optimizer \\
\hline & & 13.90 & 13.83 & 10.3895 \\
\hline & ULTC & 6 & 6 & 2 \\
\hline Switching & CS & 14 & 12 & 2 \\
\hline operations & CF1 & 10 & 10 & 3 \\
\hline \multirow{2}{*}{ of VCDs } & $\mathrm{CF} 2$ & 10 & 8 & 1 \\
\hline & CF3 & 6 & 4 & 4 \\
\hline \multicolumn{2}{|c|}{ Power loss (\$) } & 1112 & 1106.4 & 831.16 \\
\hline \multicolumn{2}{|c|}{ Switching Loss $(\$)$} & 2360 & 2080 & 600 \\
\hline \multicolumn{2}{|c|}{ Total Loss $(\$)$} & 3472 & 3186.4 & 1431.16 \\
\hline
\end{tabular}

Table 3. DG Located at Bus 8

\begin{tabular}{|c|c|c|c|c|}
\hline \multicolumn{2}{|c|}{ DG Location } & \multicolumn{3}{|c|}{ At Bus 14} \\
\hline \multirow{2}{*}{\multicolumn{2}{|c|}{$\begin{array}{l}\text { Control Methods } \\
\text { Power loss (MWh) }\end{array}$}} & Conventional & Dynamic programming & Grey wolf optimizer \\
\hline & & 14.07 & 14.01 & 10.9509 \\
\hline \multicolumn{2}{|c|}{$\begin{array}{r}\text { Power loss (MWh) } \\
\text { ULTC }\end{array}$} & 6 & 6 & 1 \\
\hline Switching & CS & 14 & 12 & 0 \\
\hline operations & CF1 & 10 & 10 & 1 \\
\hline \multirow[t]{2}{*}{ of VCDs } & $\mathrm{CF} 2$ & 10 & 8 & 1 \\
\hline & $\mathrm{CF} 3$ & 8 & 6 & 1 \\
\hline \multicolumn{2}{|c|}{ Power loss $(\$)$} & 1125.6 & 1120.8 & 876.072 \\
\hline \multicolumn{2}{|c|}{ Switching Loss $(\$)$} & 2440 & 2160 & 200 \\
\hline \multicolumn{2}{|c|}{ Total Loss $(\$)$} & 3565.6 & 3280.8 & 1076.072 \\
\hline
\end{tabular}

Table 4. DG Located at Bus 14 
Table 5. Cost Comparis on of Different Algorithms

\begin{tabular}{|c|c|c|c|c|c|c|c|c|c|}
\hline DG location & \multicolumn{3}{|c|}{ At 5} & \multicolumn{3}{|c|}{ At 8} & \multicolumn{3}{|c|}{ At 14} \\
\hline Control Methods & $\mathrm{CO}$ & $\overline{\mathrm{DP}}$ & GWO & $\mathrm{CO}$ & $\mathrm{DP}$ & GWO & $\mathrm{CO}$ & DP & GWO \\
\hline Power loss $(\$)$ & 1095.2 & 1093.6 & 930.352 & 1112 & 1106.4 & 831.16 & 1125.6 & 1120.8 & 876.072 \\
\hline Switching Loss $(\$)$ & 2360 & 1920 & 360 & 2360 & 2080 & 600 & 2440 & 2160 & 200 \\
\hline Total $\operatorname{Loss}(\$)$ & 3455.2 & 3013.6 & 1290.352 & 3472 & 3186.4 & 1431.16 & 3565.6 & 3280.8 & 1076.07 \\
\hline Power loss comp & $\mathrm{n}(\$)$ & 0.1460 & 15.051 & & 0.503 & 25.255 & & 0.426 & 22.168 \\
\hline Switching Loss con & $\operatorname{son}(\$)$ & 18.644 & 84.745 & & 11.864 & 74.576 & & 11.475 & 91.803 \\
\hline Total cost comp & $\mathrm{n}(\$)$ & 12.780 & 62.654 & & 8.225 & 58.779 & & 7.987 & 69.82 \\
\hline
\end{tabular}

\section{CONCLUSION}

The following conclusions are derived based on the results:

a. Power loss reduction: proposed method reduced power loss maximu m by $25.2554 \%$ and minimum by $15.05 \%$ compared with conventional and $24.88 \%$ maximu $\mathrm{m}$ and $14.93 \%$ minimum compared with DP.

b. Switching loss: proposed method reduced switching loss maximu m by $91.80 \%$ and minimum by $74.57 \%$ compared with conventional and $90.74 \%$ maximum and $71.15 \%$ minimum compared with DP.

c. Total loss: proposed method reduced total loss maximu $\mathrm{m}$ by $69.82 \%$ and minimum by $58.78 \%$ compared with conventionaland $67.20 \%$ maximum and $55.08 \%$ minimum compared with DP.

\section{REFERENCES}

[1] H Jiayi, J Chuanwen, X Rong. "A review on distributed energy resources and micro grid”. Renew. Sustain. Energy Rev. 2008; 12(1): 2472-2483.

[2] A K Arani. "Optimal placement and sizing of distributed generation units using Co-Evolutionary particle swarm optimization algorithms”. TELKOMNIKA Indonesian Journal of Electrical Engineering. 2015; 13(2): 247-256.

[3] P S Meera, S Hemamalini. "Optimal siting of distributed generators in a distribution network using Artificial Immune Sy stem”. International Journal of Electrical and Computer Engineering (IJECE). 2017; 7(2): 641-649.

[4] N Manoj Kumar, V K Sethi. "Optimal location of distributed generation and its impacts on voltage stability". International Journal of Electrical and Computer Engineering (IJECE). 2016; 6(2): 501-511.

[5] J O Petinrin, J O Agdolade, M Shaaban. "Voltage regulation in a Microgrid with hybrid PV/Wind energy". TELKOMNIKA Indonesian Journal of Electrical Engineering. 2015; 14(3): 402-409.

[6] Ruey Hsun, L Chen Kuo. "Dispatch of main transformer ULTC and capacitors in a distribution system". IEEE Transactions on Power Delivery. 2001; 16(4): 625-630.

[7] J O Donnel. "Voltage management of networks with distributed generation". PhD thesis. Edinburgh \& U.K.; 2007.

[8] F A Vivan. "Voltage control and voltage stability of power distribution systems in the presence of distributed generation". PhD thesis. Sweden \& U.T.; 2008.

[9] F C Lu, Y Y Hsu. "Reactive power/voltage control in a distribution substation using dynamic programming". Proc. Inst. Elect. Eng., Gen., Trans., Dist.1995; 142(6): 639-645.

[10] F A Vivan, D Karlsson. "Combined local and remote voltage and reactive power control in the presence of induction machine distributed generation". IEEE Transactions on Power Systems. 2007; 22(4): 2003-2012.

[11] F A Vivan, D Karlsson. "Voltage and reactive power control in systems with sy nchronous machine based distributed generation". IEEE Transactions on Power Delivery. 2008; 23(2): 1079-1087.

[12] C J Dent, L F Ochoa, G P Harrison. "Network distributed generation capacity analy sis using OPF with voltage step constraints". IEEE Transactions on Power Systems. 2010; 25(1): 296-304.

[13] A R Ahmadi, T C Green. "Optimal power flow for autonomous regional active network management system". IEEE Power \& Energy Society General Meeting. 2009; 1-7.

[14] W Sheng, K Y Liu, Y S Cheng. "A trust region SQP method for coordinated voltage control in smart distribution sy stem". IEEE Transactions on Smart Grid. 2015; 7(1): 381-391.

[15] H Li, F Li, Y Xu, D T Riyaz, J D Kueck. "Adaptive voltage control with distributed energy sources: Algorithm, theoretical analysis, simulation, and field test verification”. IEEE Transactions on Power Systems. 2010; 25(3): $1638-1647$.

[16] Y J Kim, S J Ahn, P I Hwang, P G Chan, S I Moon. "Coordinated control of a DG and voltage controlled devices using a dynamic programming algorithm". IEEE Transactions on Power Systems. 2013; 28(1): 42-51.

[17] W Sheng, K Y Liu, Y Liu, X Ye, H Kaiyuan. "A reactive power coordination optimization method with renewable distributed generation based on improved harmony search". IET Generation, Transmission \& Distribution. 2016; 10(13): 3152-3162.

[18] J Hetzer, David C Yu. "An economic dispatch model incorporating wind power". IEEE Transactions on Energy Conversion. 2008; 23(2): 603-611.

[19] A Feijoo, J Cidras. "Modelling of wind farms in the load flow analysis". IEEE Transactions on Power Systems. 2000; 15(1): 110-115.

[20] J F M Padron, A E F Lorenzo. "Calculating steady-state operating conditions for doubly-fed induction generator wind turbines". IEEE Transactions on Power Systems. 2010; 25(2): 922-928.

[21] J H Holland. "Genetic Algorithms. Scientific American". 1992; 267(1): 66-72.

[22] D Goldberg. "Genetic Algorithms in optimization search and machine learning". Addison Wesley, New York. 1995. 
[23] R Storn, K Price. "Differential evolution- a simple and efficient heuristic for global optimization over continuous spaces". Journal of global optimization. 1997; 11(4): 341-359.

[24] X Yao, Y Liu, G Lin. "Evolutionary programming made faster". IEEE Transactions on Evolutionary Computation. 1999; 3(2): 82-102.

[25] D Fogel. "Artificial Intelligence through simulated evolution". Wiley-IEEE press. 2009.

[26] B Webster, P J Bernhard. "A Local search optimization algorithm based on natural principles of gravitation". International Conference on Information and Knowledge Engineering. Las Vegas. USA. 2003; 255-261.

[27] O K Erol, I Eksin. "A new optimization method: big bang-big crunch". Advances in Engineering Software. 2006; 37(2):106-111.

[28] E Rashedi, H Nezamabadi Pour, S Saryazdi. "GSA: a gravitational search algorithm”. Information sciences. 2009; 179(13): 2232-2248.

[29] B Alatas. "ACROA: Artificial Chemical Reaction Optimization Algorithm for global optimization". Expert Systems with Applications. 2011;38(2): 13170-13180.

[30] M Roth. "Termite: A swarm intelligent routing algorithm for mobile wireless ad-hoc networks". Wireless Intelligent Systems Laboratory. New york. 2005; 1-31.

[31] X Lu, Y Zhou. "A novel global convergence algorithm: bee collecting pollen algorithm". International Conference on Advanced Intelligent Computing Theories and Applications. Springer. Shanghai. China. 2008; 518-525.

[32] A Mucherino, O Seref. "Monkey search: a novel met heuristic search for global optimization". AIP conference proceedings. Gainesville. Florida. 2007; 162-173.

[33] P C Pinto, T A Runkler, J M Sousa. "Wasp swarm algorithm for dynamic max- sat problems". $8^{\text {th }}$ International conference on Adaptive and Natural Computing algorithms. Springer. 2007. 350-357.

[34] S Mirjalili, S M Mirjalili, A Lewis. "Grey Wolf Optimizer". Advances in Engineering Software. 2014; 69(1): 4661.

\section{BIOGRAPHIES OF AUTHORS}

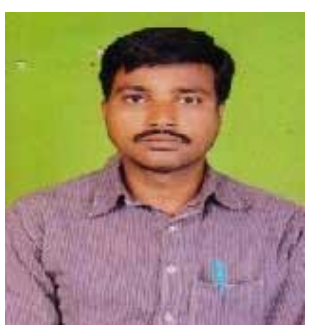

M. Sankaraiah has obtained his B.Tech degree from S.V.University and M.Tech degree from N.I.T,Calicut. He has 10 years of teaching experience. He published 4 research papers at International level. He is presently a research scholar at JNTUA,Anantapur,A.P. He is working in the area of Distributed Generation, FACTS Controllers\& Algorithms.

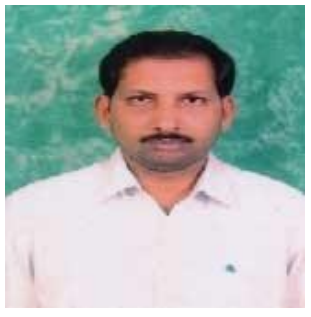

S. Suresh Reddy has obtained his M.Tech degree and Ph.D degree from JNTU, Hyderabad. He has 13 years of teaching experience. He published 10 research papers at National and International level. Hisresearch area is FACTS Controllers and Distributed Generation.

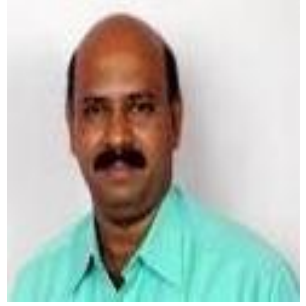

M. Vijaya Kumar has obtained his M.Tech from NIT,Warangal and Ph.D from JNTU,Hyderabad. He has 23 years of teaching experience. He has published 45 research papers at National and International level. His research area is Power Quality Improvement in Power Systems. 